\title{
ILISU BARAJI DOLUSAVAK HAVALANDIRICISI PERFORMANS ANALIZI
}

\author{
M. Cihan AYDIN ${ }^{1}$ (ORCID: 0000-0002-5477-1033)* \\ Cesur KAPLAN² (ORCID: 0000-0002-4899-1814) \\ ${ }^{I}$ Bitlis Eren Üniversitesi İnşaat Mühendisliği Bölümü, Bitlis \\ ${ }^{2}$ D.S.İ. Ilısu Projesi 16. Bölge Müdürlügü, Mardin
}

Gelis/Received: 14.08 .2018 Kabul / Accepted: 12.04.2019

\begin{abstract}
ÖZ
Yüksek akım hızlarına maruz dolusavak şut kanalları kavitasyon hasarından korumanın en etkili yöntemi havalandıııc kullanmaktadır. Bu çalışmada, Ilısu Barajı dolusavak havalandırıcılarının 1982 ilk tasarımı ile 2010 revize tasarımının performansları Hesaplamalı Akışkanlar Dinamiği (HAD) yöntemi kullanılarak incelenmiştir. İlk olarak 1982 ilk tasarımının üç boyutlu HAD analizleri yapılmış ve havalandırıcı performansının yetersiz olduğu tespit edilmiştir. İkinci olarak, 2010 revize tasarımının sayısal modellemesi yapılarak havalandırıcı performansı çalışılmıştır. Daha önce 2010 revize tasarımı için kapsamlı olmayan bir sayısal çalışma yapılmış fakat farklı akım koşulları için detaylar ilk kez bu çalışmada verilmiştir. Her iki tasarımın detaylı HAD sonuçları verilmiş ve karşılaştırmalı olarak değerlendirilmiştir. HAD analizlerinden elde edilen sonuçlar 2010 revize tasarımın havalandırma performansının çok daha iyi olduğunu göstermiş ve bu tasarımın dolusavak şut kanallarını kavitasyon hasarından yeterince koruyabileceği sonucuna varılmıştır.
\end{abstract}

Anahtar kelimeler: Ilısu barajı, dolusavak, kavitasyon, havalandırıc1, HAD.

\section{PERFORMANCE ANALYSIS OF ILISU DAM SPILLWAY AERATOR}

\begin{abstract}
In order to prevent cavitational damage on the spillway chutes exposed to high flow velocity, the most effective method is to use aerator devices. In this study, the first design of the Ilisu Dam spillway aerator in 1982 and the performance of the 2010 revision design were investigated using the Computational Fluid Dynamics (CFD) method. First, three-dimensional CFD analysis of the initial 1982 design was conducted and it was determined that the performance of the aerator was inadequate. Secondly, numerical modeling of the 2010 revised design was performed and the aerator performance was studied. Before an incomprehensive study were performed for the revised design of 2010, but the detailed numerical analysis for different flow conditions is presented in this study. The CFD results of both designs are given and evaluated comparatively. The results from the CFD analyzes showed that the aeration performance of the 2010 revised design was much better than the previous one to adequately protect the spillway chute channels from cavitation damage.
\end{abstract}

Keywords: Ilısu dam, spillway, cavitation, aerator, CFD

\footnotetext{
${ }^{*}$ Corresponding author / Sorumlu yazar. Tel.: +90(434) 222 0030; e-mail / e-posta: mcaydin@ gmail.com
} 


\section{GíRiş}

Dolusavaklar taşkın anlarında meydana gelen maksimum debinin baraj üzerinden atılarak korunmasına yardımcı olan emniyet yapılarıdır. Yüksek miktardaki debi gelende dolusavaklarla birlikte kullanılan şut kanalları ile barajdan uzaklaştırılır. Şut kanalı üzerinde mansaba doğru kot farkından dolayı hızlanan yüksek debi ve hızdaki akım şut kanalları üzerinde kavitasyon üreterek beton yüzeylerde ciddi tahribatlara neden olabilmektedir. Şut kanalı üzerindeki yüksek hızlardan dolayı beton yüzeydeki derz, kalıp kusurları gibi düzensizliklerde meydana gelen düşük basınçların buhar basıncı altına kadar düşmesi kavitasyonu başlatarak akım içerisinde buhar kabarcıkları üretir. Akımla birlikte ilerleyen buhar kabarcıkları tekrar normal basınç seviyesiyle karşılaştığında büyük gürültülerle patlayarak su fazına geçerken betona zarar verir. Başlayan oyulma etkisi daha büyük kavitasyon bölgeleri oluşturarak şut kanalları üzerinde giderek büyüyen ciddi hasarlara neden olur. 1970 ve 1980 yılları arasında Türkiye'deki Keban Barajı ve İran'daki Karun Barajında meydana gelen büyük ölçekli kavitasyon hasarları bu olaya bilim dünyasının ilgisini çekmiştir. Literatürde, akım hızlarının yaklaşık olarak 20-30 m/s'yi aştığı durumlarda kavitasyon hasarı oluşabileceği kabul edilmektedir [1-4]. Bu durumda şut kanallarını kavitasyon hasarlarından koruyabilmenin en etkili yolu havalandırıcılar kullanarak kavitasyon riski olan bölgeyi havalandırmaktır. Akım altına yerleştirilen hava kanallarını vasıtasıyla oluşturulan düşük basınç bölgelerine atmosfere açılan hava bacalarından doğal bir mekanizmayla hava çekilerek akım havalandırılır. Böylece akıma karıșan belli miktardaki hava kavitasyon etkisi sönümleyerek oluşacak hasarı engeller. Gerekli hava konsantrasyonu havalandırıcının boyutları ve tasarımıyla ilgilidir.

Geçmişte şut havalandırıcılarıyla ilgili birçok kapsamlı deneysel çalışma yapılmıştır. İlk olarak Volkart ve Chervet [5] farklı tipteki havalandırıcılar üzerinde hidrolik model çalışmaları yürütmüş ve havalandırma performanslarını karşılaştırmıştır. Pinto [4] kavitasyon ve havalandırmayla ilgili kapsamlı bir kaynak sunmuş, kavitasyon olayı ve havalandırmayı teorik ve deneysel yaklaşımlarla detaylı olarak analiz etmiştir. Kesin limitler verilmese de bir kural olarak havalandırıcı kullanımının yüzeydeki iyileştirme ve güçlendirmelerden çok daha pratik ve ekonomik olacağını vurgulamıştır [4]. Kells ve Smith [6], kavitasyon önlemek için kullanılan dolusavak havalandırıcıları üzerine kapsamlı bir literatür taraması yaparak konuyla ilgili bulgu ve bağıntıları bir araya getiren faydalı bir derleme sunmuşlardır. Kobus ve Koschitzky [7], Hidrolik yapılardaki serbest yüzeyli akımların yerel havalandırması üzerinde durmuşlardır. Araştırmacılar, önemli bir sonuç olarak, nap altındaki atmosfer altı basınçlar hava giriş oranına ve hava bacasının sürtünme direncine bağlı olduğunu ve eğer baca kapalı tutulursa basınç farkı maksimuma ulaşırken hava girişi sıfır olacağını belirmişlerdir. Rutschmann [8], Rutschmann ve Volkart [9], dolusavak şut kanalı genişliği boyunca boşluk alt basınçlarının değişimini incelemiş ve Euler sayısının 50'nin üzerine çıktığı zaman havalandırıcı üzerindeki su jeti geometrisinin boşluk alt basınçlarından etkileneceği sonucuna varmışlardır. Chanson [1], havalandırıcılar üzerindeki havalandırma bölgelerini tanımlamış ve alt nap ve üst naptan giren toplam hava konsantrasyonunu deneysel ve teorik olarak belirlemeye çalışmıştır. Rutshmann ve Hager [10], verilen bir havalandırıcının hava giriş oranını basınç sayısı ve Froude sayısına bağlı veren bir bağıntı sunmuştur. Ayrıca havalandırıcı üzerindeki serbest jet uzunluğu veren teorik bir bağıntı elde etmişlerdir. Kökpınar ve Göğuş [11], dolusavak havalandırıcıları üzerinde kapsamlı bir deneysel çalışma yürütmüş ve hava giriş oranını boyutsuz jet uzunluğuna bağlı olarak veren ampirik bir bağıntı elde etmişlerdir. Yapılan hidrolik model deneylerinde ölçek etkilerini dikkate alarak elde edilen deneysel sonuçlardan prototip sonuçları elde etmek için bazı bağıntılar sunulmuştur. Kökpınar ve Göğüş'ün [11] sunduğu bağıntılar deneysel çalışma yürüten DSİ gibi uygulamacılar tarafından model deneylerinde de kullanılmaktadır.

Son yıllarda, Pfister ve Hager [12, 13], Pfister vd. [14] dolusavak havalandırıcılarının hava taşıma karakteristikleri, hidrolik tasarımları ve havalandırıcı öncesi yaklaşım akım karakteristikleri üzerinde kapsamlı deneysel çalışmalar yürütmüşlerdir. Pfister vd. [14] farklı eğimlerdeki havalandırıcı saptırıcıları ve nap altı boşluk altbasınçlarının havalandırıcı performansı üzerine etkisini incelemiştir. Qian vd. [15] ejderha kuyruk tipi dolusavak şut kanallarındaki havalandırıcı altındaki boşluğa su dolmasını kontrol etmek için bir dizi teorik ve deneysel çalışmalar yapmışlardır. Geleneksel olarak konuyla ilgili çalışmalar fiziksel model deneyleriyle yürütülmekle birlikte son yıllarda gelişen bilgisayar ve hesaplama tekniklerinin kullanıldığı sayısal dinamik modeller oldukça etkili sonuçlar verdiği görülmektedir. Aydın [16] ve Öztürk vd. [17] alttan alışlı havalandırıcı adı verdikleri bir havalandırıcı tipi önermiş ve havalandırıcıları analiz etmek için ilk kez Hesaplamalı Akışkanlar Dinamiği (HAD) yöntemini kullanmışlardır. Aydın [18] ayrı bir çalışmada alttan alışlı havalandırıcıları deneysel olarak çalışmış ve diğer araştırmacılar tarafından sunulan havalandırıcı performanslarıyla karşılaştırmıştır. Teng ve Yang [19] fiziksel model testlerine ek olarak akımdaki su-hava davranışını belirlemek için HAD tekniğinden faydalanmıştır. Benzer şekilde Kumcu [20] bir baraj dolusavağı ve üzerindeki havalandırıcının performansını belirlemek için deneysel ve sayısal yöntemleri birlikte kullanmıştır. HAD analizlerinden elde edilen sonuçların deneysel çalışmalarla çok iyi uyuştuğunu bildirmiştir. 


\section{MATERYAL VE METOT}

\subsection{Ilısu Barajı ve Dolusavak Karakteristikleri}

Enerji üretmek amacıyla inşa edilen Ilısu Barajının kurulu gücü 1200 MW, yıllık üretmesi beklenen enerji ise $4120 \mathrm{GWh} / \mathrm{y}$ l'dır. Bu güç Türkiye'deki Hidroelektrik santralleriyle üretilen enerjinin yaklaşık \% 10'luk bir kısmına denk gelecek olup barajın işletime açılmasıyla 400 Milyon Dolar/yıl gelir getirmesi beklenmektedir. İnşaatı 2009 yılında başlayan barajın yapımı hala devam etmektedir. Barajla ilgili bazı karakteristikler Tablo 1'de verilmiştir.

Tablo 1. Ilısu Baraj1 Bazı Karakteristikleri [21]

\begin{tabular}{|l|l|}
\hline Maksimum Su Seviyesi & $527.86 \mathrm{~m}$ \\
\hline Normal Su Seviyesinde Toplam Rezervuar Alanı & $10410 \times 10^{6} \mathrm{~m}^{3}$ \\
\hline Tipi & Önyüzü Betonla Kaplı Kaya Dolgu Baraj \\
\hline Talveg Kotu & $400.00 \mathrm{~m}$ \\
\hline Gövde Dolgu Hacmi & $23.7 \times 10^{6} \mathrm{~m}^{3}$ \\
\hline Kret Genişliği & $9.02 \mathrm{~m}$ \\
\hline Kret Uzunluğu & $2327 \mathrm{~m}$ \\
\hline Kret Kotu & $530 \mathrm{~m}$ \\
\hline Beton Barajı Temelden Yüksekliği & $51.50 \mathrm{~m}$ \\
\hline Dolusavak Kapasitesi & $17988 \mathrm{~m}^{3} / \mathrm{s}$ \\
\hline Dolusavak Tipi & Radyal Kapaklı, Sıçratma Eşikli Dolusavak \\
\hline Toplam Kurulu Güç & $1200 \mathrm{MW}$ \\
\hline Ortalama Yıllık Enerji Üretimi & $4120 \mathrm{GWh}$ \\
\hline Türbin Tipi & Düşey Francis \\
\hline
\end{tabular}

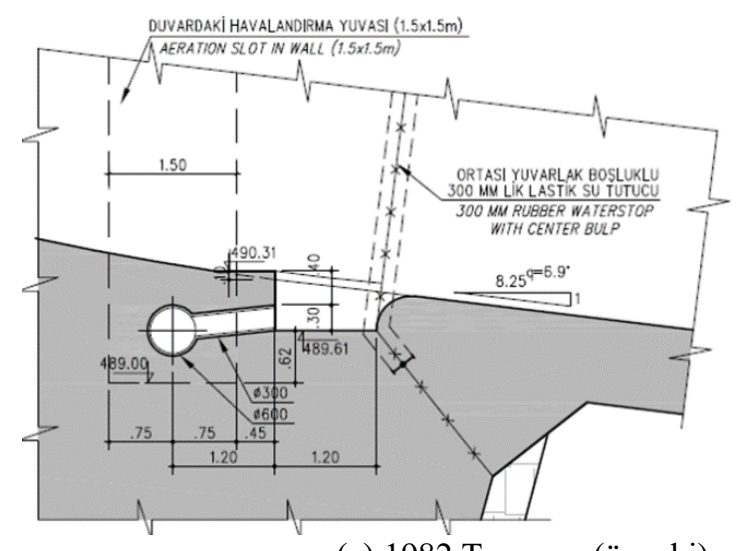

(a) 1982 Tasarımı (önceki)

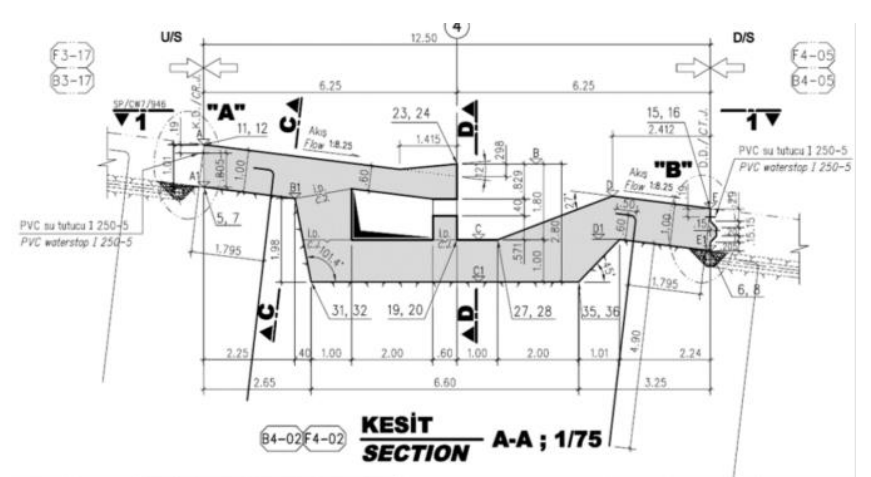

(b) Revize tasarım (yeni)

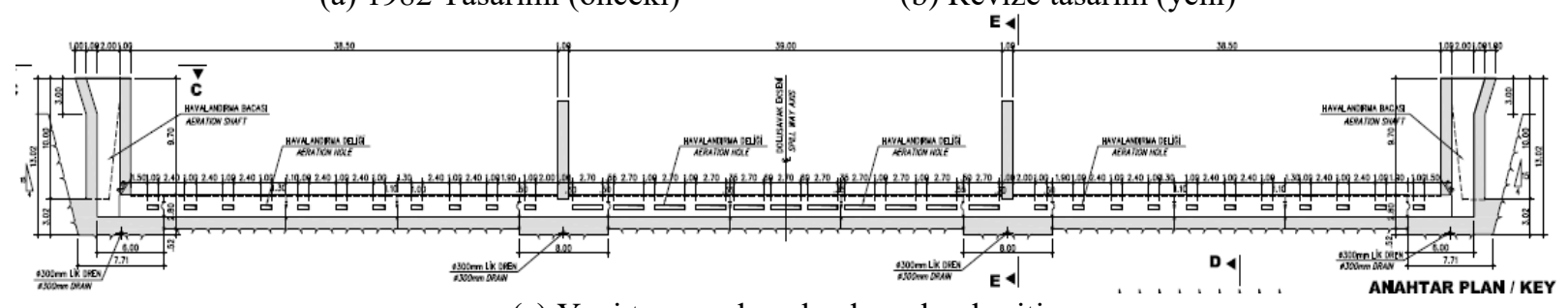

(c) Yeni tasarım havalandırıcı boykesiti

Şekil 1. Ilısu Baraj dolusavak havalandırıcısının eski ve yeni tasarım detayları [21] 


\subsection{Yöntem}

Hesaplamalı Akışkanlar Dinamiği (HAD) gelişen bilgisayar ve sayısal hesaplama tekniklerinin gelişmesiyle son yıllarda kullanımı yaygınlaşmıştır. Hidrolik yapılarda HAD kullanımıyla ilgili detaylar örnekleriyle birlikte Aydın [22] tarafından verilmiştir. Bu çalışmada, yaygın olarak kullanılan HAD yazılımlarından biri olan ANSYS-Fluent programı kullanılmıştır. ANSYS-Fluent'te çok fazlı akımlar için Volume of Fluid (VOF) metodu önerilmektedir. Bu akım modelinde birincil faz sürekli ortam akışkanı, diğeri ise bu akışkan içine dağılmış olan ikincil faz olarak tanımlanır. Atmosfere serbest yüzeyli akımlar için bu durum, sürekli ortam akışkanı hava, ikincil faz ise su olarak alınabilir. Çok fazlı akımlarda sonlu eleman ağları ile bölünmüş her bir hücre akışkanın belirli hacim oranlarıyla işgal edilir. " $k$ " akışkanın hacim oranı için üç durum söz konusudur: $\mathcal{E}_{k}=0$ ise $\boldsymbol{k}$ akışkanın hücresi boş, $\mathcal{E}_{k}=0$ ise $\boldsymbol{k}$ akışkanı hücreyi tamamen doldurmuş, $0 \leq \mathcal{E}_{k} \leq 1$ ise hücre iki akışkan tarafından doldurulmuş olup akışkanlar arasında bir arayüzey içermektedir (hava ile su arasında oluşan serbest yüzeyi temsil etmektedir). Serbest yüzeyli akımlarda kullanılan VOF modelinin süreklilik ve momentum denklemleri sırasıyla aşağıda verilmiştir [23]:

Süreklilik denklemi:

$\frac{\partial_{\varepsilon_{k}}}{\partial_{t}}+u_{i} \frac{\partial_{\varepsilon_{k}}}{\partial_{x_{i}}}=S_{\varepsilon_{k}}$

$\sum_{k=1}^{n} \varepsilon_{k}=1$

Modelin momentum denklemi:

$\frac{\partial}{\partial_{t}}\left(\rho u_{i}\right)+\frac{\partial}{\partial_{x_{i}}}\left(\rho u_{i} u_{j}\right)=-\frac{\partial P_{s}}{\partial_{x_{j}}}+\frac{\partial}{\partial_{x_{i}}} \mu\left(\frac{\partial_{u_{i}}}{\partial_{x_{j}}}+\frac{\partial_{u_{j}}}{\partial_{x_{i}}}\right)+\rho g_{j}+F_{j}$

Burada; $\rho$ : Akışkanın yoğunluğu, $\mu$ :Akışkanın dinamik viskozitesi, $u$ :Akışkanın hızı (hız vektörü), $P_{s}$ : Basınç, $g$ :yerçekim ivmesi, $F_{j}$ : Kütle kuvvetleridir.

Türbülans modeli olarak birçok çalışmada test edilmiş olan Realizable $k-\varepsilon$ model kullanılmış olup denklemleri aşağıda verilmiştir:

$$
\begin{aligned}
& \frac{\partial}{\partial_{\mathrm{t}}}(\mathrm{pk})+\frac{\partial}{\partial_{\mathrm{x}_{\mathrm{j}}}}\left(\rho \mathrm{ku}_{\mathrm{j}}\right)=\frac{\partial}{\partial_{\mathrm{x}_{\mathrm{j}}}}\left[\left(\mu+\frac{\mu_{\mathrm{t}}}{\sigma_{\mathrm{k}}}\right) \frac{\partial_{\mathrm{k}}}{\partial_{\mathrm{x}_{\mathrm{j}}}}\right]+\mathrm{G}_{\mathrm{k}}+\mathrm{G}_{\mathrm{b}}-\rho \varepsilon-\mathrm{Y}_{\mathrm{M}}+\mathrm{S}_{\mathrm{k}} \\
& \frac{\partial}{\partial_{\mathrm{t}}}(\rho \varepsilon)+\frac{\partial}{\partial_{\mathrm{x}_{\mathrm{j}}}}\left(\rho \varepsilon \mathrm{u}_{\mathrm{j}}\right)=\frac{\partial}{\partial_{\mathrm{x}_{\mathrm{j}}}}\left[\left(\mu+\frac{\mu_{\mathrm{t}}}{\sigma_{\varepsilon}}\right) \frac{\partial_{\varepsilon}}{\partial_{\mathrm{x}_{\mathrm{j}}}}\right]+\rho \mathrm{C}_{1} \mathrm{~S}_{\varepsilon}-\rho \mathrm{C}_{2} \frac{\varepsilon^{2}}{\mathrm{k}+\sqrt{\mathrm{v} \varepsilon}}+\mathrm{C}_{1_{\varepsilon}} \frac{\varepsilon}{\mathrm{k}} \mathrm{C}_{3_{\varepsilon}} \mathrm{G}_{\mathrm{b}}+\mathrm{S}_{\varepsilon}
\end{aligned}
$$

Model sabitlerinin varsayılan olarak aşağıdaki gibi alınması önerilmektedir:

$$
C_{1 \varepsilon}=1.44, C_{2}=1.9, \sigma_{k}=1.0, \sigma_{\varepsilon}=1.2
$$

Buradaki; $G_{b}$ : Yüzdürme nedeni ile türbülans kinetik enerjisinin üretimi. $Y_{M}$ : Sıkıştırılabilinir türbülanstaki dalgalı genişlemeninin toplam dağılım oranına katkısını, $C_{2}$ ve $C_{l \epsilon}$ : Sabitleri, $\sigma_{k}$ ve $\sigma_{\epsilon}: k$ ve $\epsilon$ için Prandtl türbülans sayılarını, $S_{k}$ ve $S_{\epsilon}$ : Kullanıcılar tarafından tanımlanan kaynak terimlerinidir. 


\section{BULGULAR VE TARTIŞMA}

\subsection{Tasarımı}

Detayı Şekil 1'de verilmiş olan 1982 tasarımının üç boyutlu model geometrisi hazırlanmış ve öncelikle sonuçların ağ yapısına duyarlılığını görebilmek için farklı boyuttaki meş yapıları kullanılmıştır. Şekil 2'de görüldüğü gibi, kaba meş için 1640053, ince meş yapısı için ise 2904186 adet hibrid hücreden oluşan yapılar seçilmiştir. Havalandırıcı detayları, tabana yakın bölgeler gibi akımın kritik yerlerine olayı daha iyi yansıtabilmesi için daha hassas meşleme yapılmıştır. Nihai meş durumu için minimum orthogonal quality=0.203 olarak elde edilmiştir. Şekil 3'te hava giriş oranının memba Froude sayısı ile değişimi kaba ve ince meş yapısı için verilmiştir. Kaba meş için belirlilik katsayısı $R^{2}=0.72$ elde edilirken, ince (nihai) meş için $R^{2}=0.99$ gibi oldukça yüksek bir değerdedir. Bu sonuçlar meş hassasiyetinin çözümler üzerinde etkisini göstermektedir. Nihai (ince) meş sonuçlarının belirliliğinin yüksek olması, akımı daha iyi simüle ettiği ve çözümlerin meş yapısından kaynaklanan belirsizliğinin azaldığı anlamına gelmektedir. Sonuç olarak farklı meş büyüklükleriyle yapılan analizlerden meş duyarlılığının ince (nihai) meş yapısı için yeterince az olduğu görülmüştür.

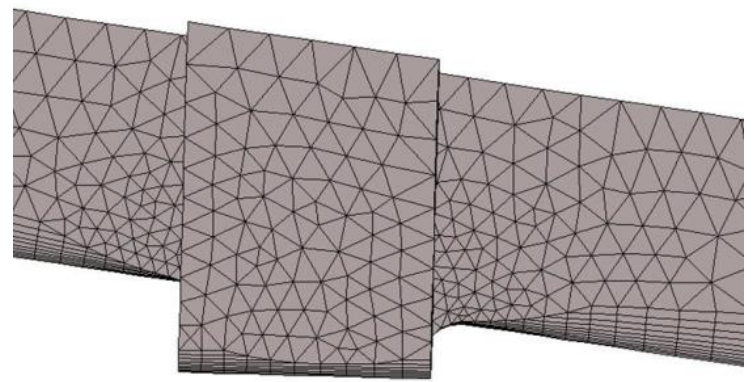

(a)

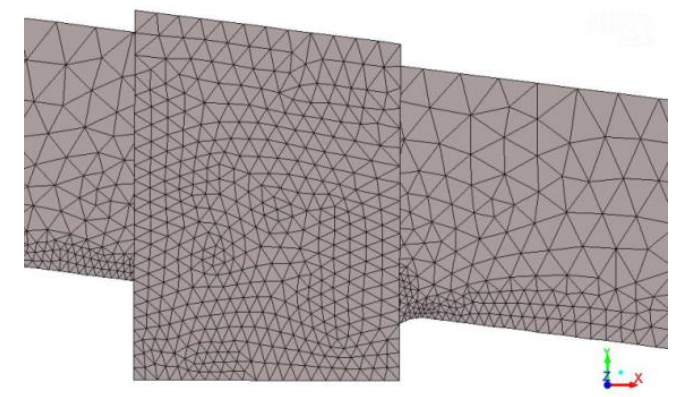

(b)

Şekil 2. 1982 tasarımının sayısal ağ yapısı: (a)Kaba meş (b) İnce meş

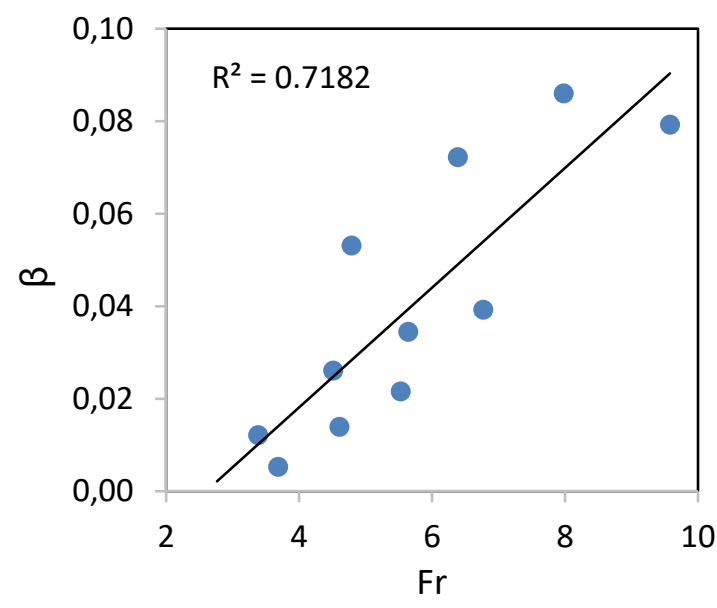

(a)

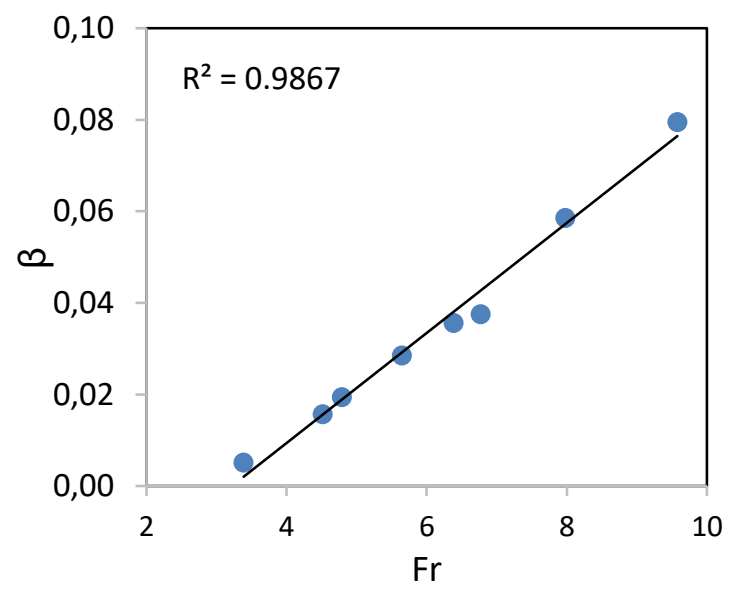

(b)

Şekil 3. Hava giriş oranlarının Fr sayısı ile değişimi: a) Kaba meş, b) Nihai meş

Ilısu Barajı Dolusavak Havalandırıcısının 1982 tasarımı kenar bacaların 2.8 x $1=2.8 \mathrm{~m}^{2}$ ve orta bacaların kesit alanı ise $2.8 \times 0.7=1.96 \mathrm{~m}^{2}$ havalandırıcı giriş alanı olmak üzere simetrik alan toplamı $A_{a}=4.76 \mathrm{~m}^{2}$ olarak verilmiştir. Simetrik modelin yarısı için çözüm yapılmış olup elde edilen değerlerin iki katı alınmıştır (Toplam baca giriş alanı $\left.=9.52 \mathrm{~m}^{2}\right)$. HAD analizleri sonucu hava giriş oranları $\left(\beta=Q_{a} / Q_{w}\right)$ ve ortalama hava konsantrasyonları $\left(C_{o}=\beta /(1+\beta)\right)$ elde edilmiştir. Buradaki $Q_{a}$ hava giriş debisi, $Q_{\underline{w}}$ su debisi, $V_{a}$ ortalama hava giriş hızıdır. Bu değer ve bağıntılar kullanılarak Tablo 2'de 1982 havalandırıcı tasarımının HAD analizlerinden 
elde edilen akımın hava giriş oranları $(\beta)$ ve hava konsantrasyonları $\left(C_{\mathrm{o}}\right)$ farklı Fr sayıları için elde edilmiştir. Russel ve Sheehan [24] malzeme testleri üzerine yaptığ 1 çalışmada kavitasyon hasarını önlemek için \%5 hava girişi sağlamanın yeterli olacağını ifade etmiştir. Aydın [25], detaylı literatür araştırması sonucu kavitasyon hasarından korunmak için akıma karıştırılması gereken ortalama hava konsantrasyonunun yaklaşık olarak en az \% 6-8 arasında olması gerektiğini belirtmiştir. Tablo 2'deki hava konsantrasyonları değerlendirdiğinde 1982 tasarımının hava konsantrasyonları verilen limit değerler altında kaldığı ve kavitasyondan korunmak için yeterli hava konsantrasyonu sağlayamadığı görülmektedir. Dolayısıyla DSİ tarafından tasarımın revize edilmesi doğru bir karar olmuştur.

Tablo 2. Ilısu Barajı dolusavak havalandırıcısı 1982 tasarımı HAD analizi sonuçları

\begin{tabular}{|c|c|c|c|c|c|c|c|c|}
\hline$H(m)$ & $V(m / s)$ & $F r$ & $\begin{array}{c}\left(V_{a}\right)_{o r t} \\
(\mathrm{~m} / \mathrm{s})\end{array}$ & $\underset{\left(m^{3} / s\right)}{Q_{a}}$ & $\underset{\left(m^{3} / s\right)}{2 Q_{a}}$ & $\underset{\left(m^{3} / s\right)}{Q_{w}}$ & $\beta$ & $\begin{array}{l}C_{o} \\
\%\end{array}$ \\
\hline 1.00 & 15 & 4.79 & 15.42 & 13.98 & 27.97 & 921.42 & 0.02 & 1.9 \\
\hline 1.00 & 20 & 6.39 & 18.19 & 34.24 & 68.47 & 1216.72 & 0.03 & 2.9 \\
\hline 1.00 & 25 & 7.98 & 20.00 & 70.32 & 140.64 & 1511.84 & 0.05 & 4.7 \\
\hline 1.00 & 30 & 9.58 & 26.74 & 114.51 & 229.03 & 1808.27 & 0.06 & 5.6 \\
\hline 2.00 & 20 & 4.52 & 23.46 & 30.24 & 60.47 & 2511.69 & 0.01 & 0.9 \\
\hline 2.00 & 25 & 5.64 & 24.84 & 68.60 & 137.19 & 3121.84 & 0.02 & 1.9 \\
\hline 2.00 & 30 & 6.77 & 28.32 & 108.08 & 216.16 & 3734.50 & 0.03 & 2.9 \\
\hline 3.00 & 25 & 4.61 & 27.82 & 50.08 & 100.16 & 4432.32 & 0.01 & 0.9 \\
\hline 3.00 & 30 & 5.53 & 29.59 & 93.39 & 186.78 & 5344.98 & 0.02 & 1.9 \\
\hline
\end{tabular}

\subsection{Revize Tasarımı}

Ilısu Barajı 2010 yılı revize tasarımının sayısal modellemesi için önceki bölümde test edilen nihai meş boyutları kullanılarak 1781717 hücreden oluşan karma ă̆ yapısı kullanılmıştır. Kullanılan sonlu hacimler hücrelerinin minimum ortogonal kalitesi \% 5, maksimum şekil oranı ise \% 55.7 olarak elde edilmiştir (Şekil 4).
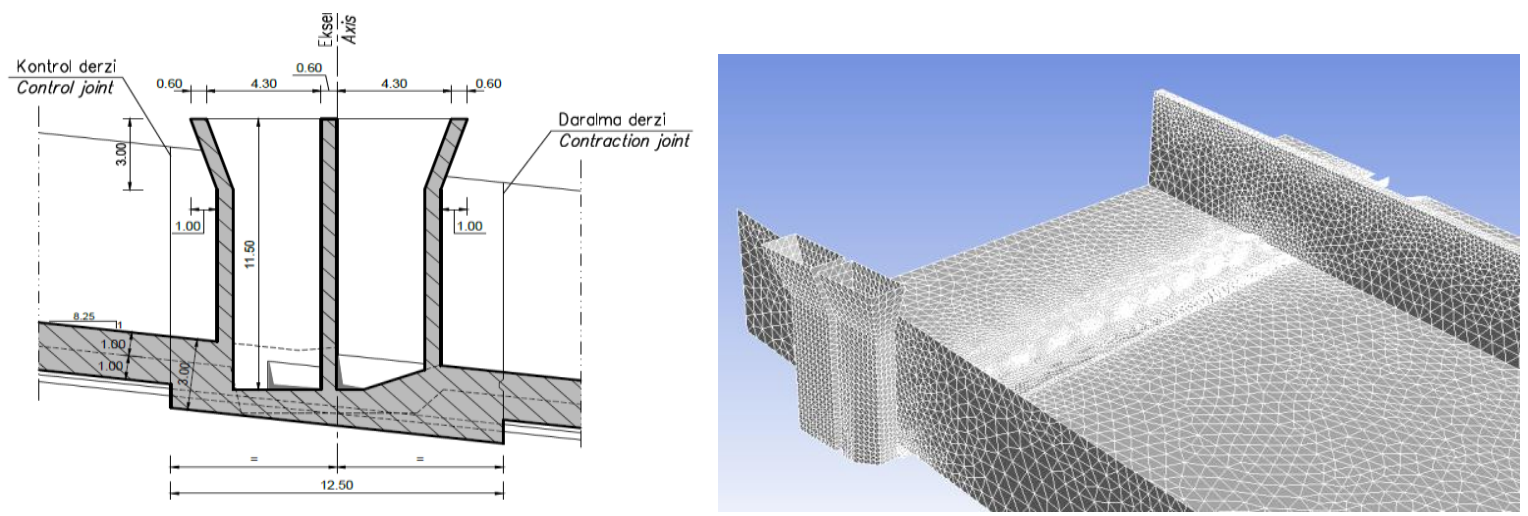

Şekil 4. 2010 revize havalandırıcı tasarımının geometrisi ve sayısal ağ yapısı

DSİ tarafından revize edilen 2010 tasarımı ile 8 olan radyal kapak sayısı 6'ya düşürülmüş, 65 m olan havalandırıcılar arası mesafe ise 75 m’ye çıkarılmıştır. Yeni tasarımda şut kanalları arasındaki bacalar kaldırılmış ana havalandırıcı kanalları ile beraber sağlı sollu ek havalandırıcı bacalar eklenmiştir. Yeni tasarımda şut kanalı üzerindeki hava kanalı (oluğu) ile taban altına yerleştirilen hava galerisi her iki tarafa yerleştirilen ayrı iki baca ile beslenmektedir. Taban altına yerleştirilen hava kanalı dikdörtgen kesitli ağızlarla ana hava oluğuna açılmakta ve böylece şut kanallarının bacadan uzak kesimlerine bile yeterli hava sağlanması amaçlanmıştır. Tasarımda dikkat çeken diğer bir önemli detay, alt tarafa yerleştirilen hava ağzı kesitlerinin kanal genişliği boyunca aynı olmayıp orta bölgelere yeterli hava sağlamak amacıyla nispeten daha büyük kesit seçilmesidir. Hesaplarda tek tarafın havalandırma bacasının giriş kesit alanı orijinal 2010 revize tasarımına göre $A_{a}=18.92 \mathrm{~m}^{2}$ olarak alınmıştır. 
Önceki tasarım olan 1982 tasarımının model deneylerinin DSİ tarafından yapılmış fakat 2010 yılı revize tasarımı için herhangi bir model çalışması yapılmamıştır. Bu revize tasarım, ilk olarak Aydın ve Kaplan [26] tarafından sayısal olarak tek bir debi için kabaca modellenmiş fakat farklı akım koşullarında detaylı analizleri yapılmamıştır. Bu çalışmada ise akım koşulları (akım derinliği ve hızları) sistematik olarak değiștirilerek farklı Froude sayıları için 2010 revize tasarımın detaylı analizleri yapılıp havalandırıcı performansı detaylı bir şekilde ortaya konmuştur. Revize tasarımının kanal boyunca havalandırılan performansını görmek için Şekil 5 'te iki farklı akım durumundaki taban hava faz oranları verilmiş̧ir. Düşük ve yüksek Froude sayılarının ikisinde de havalandırıcının kanal genişliği boyunca tabanda yeterince üniform bir hava karışımı sağlandığı görülmektedir. Şekil 5 (a) ile (b) karşılaştırıldığında hava girişinin Fr sayısıyla oldukça artmış olduğu ve jet uzunluğunun da buna bağlı attı̆̆ görülmektedir. Özellikle büyük Froude sayılarında serbest jet uzunluğunun artmasıyla nap altı hava boşluğunun büyüdüğü ve kanal genişliği boyunca bu bölgede yüksek miktarda hava girişi olduğu görülmüsstür. Düşük Froude sayılarında bile hava giriși sağlaması ise batık havalandırıcı durumunu da engellediğini göstermektedir. Şekil 6'da ise havalandırıcı tabanındaki basınçlar verilmektedir. Saptırıcı üzerinde dinamik etkilerden dolayı basınç değeri yüksekken hava oluğu üzerinde (su jeti altında) basınçlar düşüktür. $\mathrm{Bu}$ düşük basınç bölgesi sayesinde yan bacalardan hava nap altına taşınmaktadır. Elde edilen bu bulgular havalandırıcının uygun çalıştığını ve havalandırma veriminin yüksek olduğunu göstermektedir.

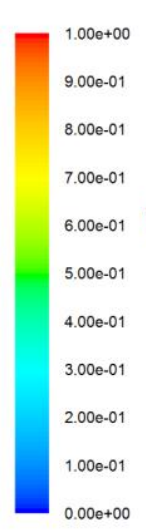

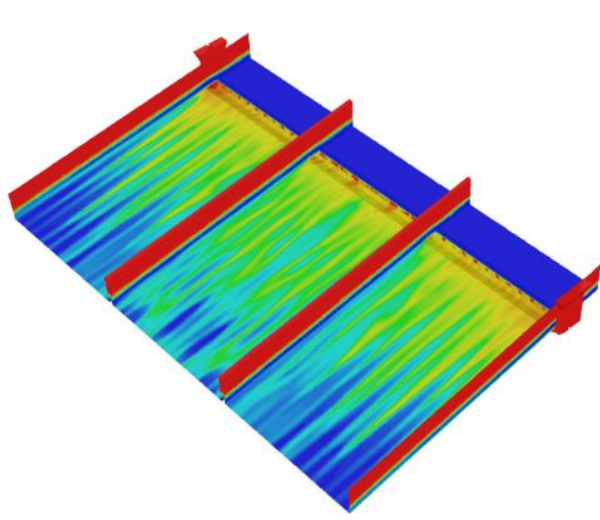

(a) $\mathrm{Fr}=3.39$

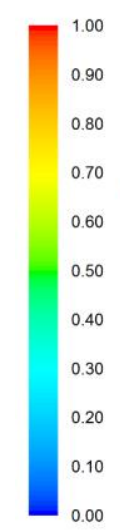

0.00

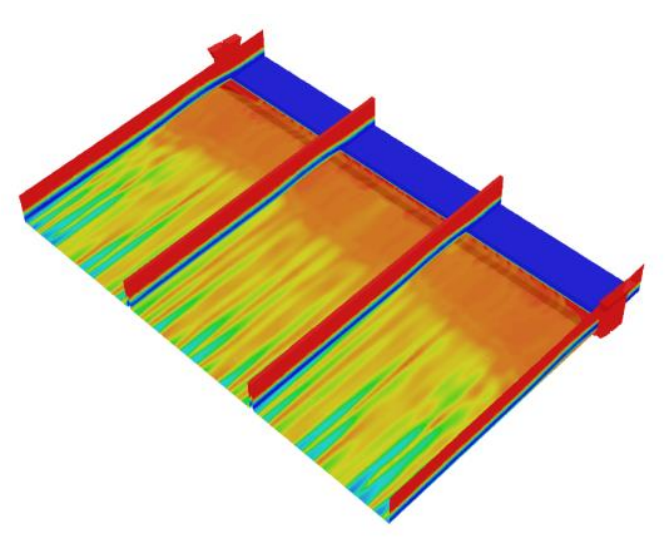

(b) $\mathrm{Fr}=6.77$

Şekil 5. Ilısu Baraj1 2010 tasarım tabandaki hava-su faz oranları: (a) $h=2.0 \mathrm{~m} V=15 \mathrm{~m} / \mathrm{s}, \mathrm{Fr}=3.39$, (b) $h=2.0$, $V=30 \mathrm{~m} / \mathrm{s}, \mathrm{Fr}=6.77$

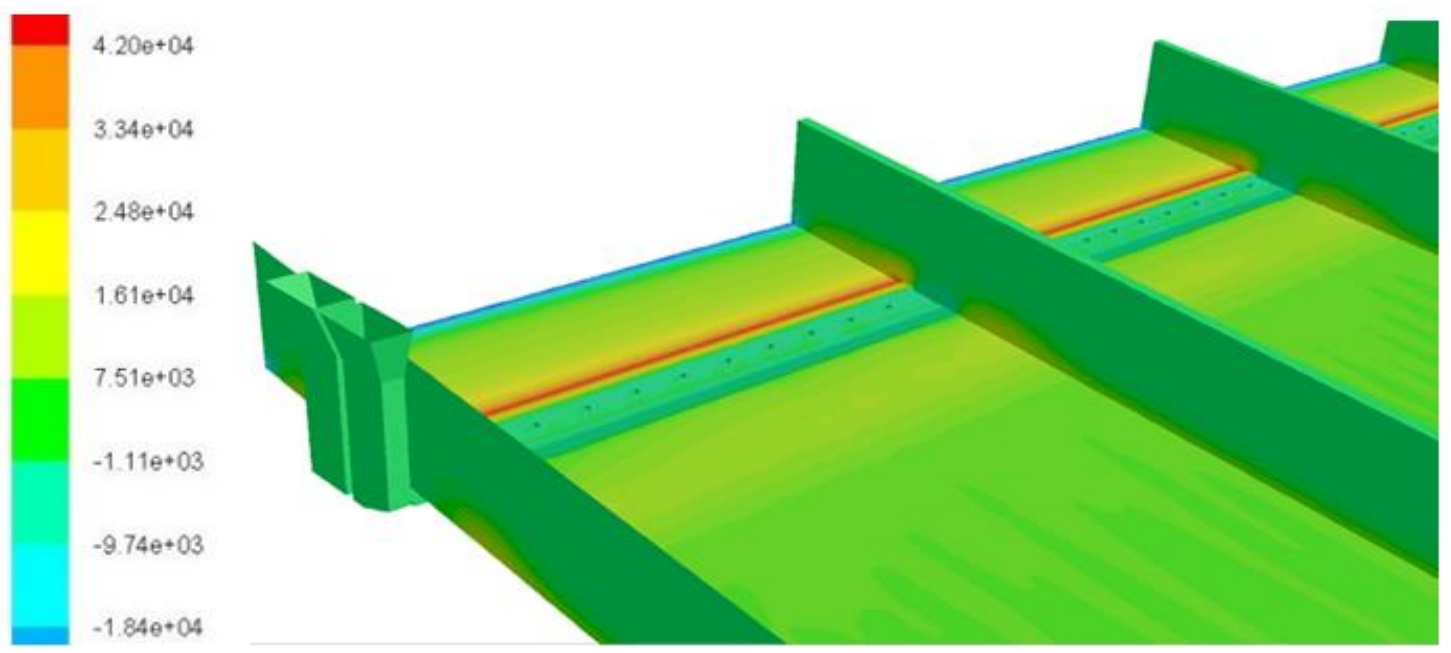

Şekil 6. Havalandırıcı tabanındaki basınç değerleri (Pa)

Tablo 3'de HAD analizlerinden elde edilen 2010 yılı tasarımının hava giriş katsayıları ve ortalama hava konsantrasyonları verilmektedir. Sonuçlar incelendiğinde hava giriş oranının $\beta=0.09 \sim 0.31$ aralığında, ortalama hava konsantrasyonun ise $C_{o}=\% 8 \sim \% 23$ aralığında olduğu görülmektedir. Bu değerlerin 1982 tasarımına göre 
oldukça yüksekte olması 2010 revize tasarımın performansının çok daha iyi olduğunu gösterir. Daha önce verilen limit değerler dikkate alındığında 2010 revize tasarım için elde edilen ortalama hava konsantrasyonu değeri kavitasyon hasarından korunmak için oldukça yeterli olacaktır.

Tablo 3. Ilısu Barajı dolusavak havalandırıcısı 2010 revize tasarımı havalandırma performansları

\begin{tabular}{|c|c|c|c|c|c|c|c|c|c|c|}
\hline$h$ & $V$ & \multirow{2}{*}{$\mathbf{F r}$} & $V_{\mathbf{a}}$ & $Q_{a}$ & $2 \times Q_{a}$ & $Q_{w}$ & $2 \times Q_{w}$ & \multirow{2}{*}{$\beta$} & \multirow{2}{*}{$C_{0}$} & \multirow{2}{*}{$\begin{array}{l}C_{0} \\
\%\end{array}$} \\
\hline (m) & $(\mathrm{m} / \mathrm{s})$ & & $(\mathrm{m} / \mathrm{s})$ & $\left(\mathrm{m}^{3} / \mathrm{s}\right)$ & $\left(\mathrm{m}^{3} / \mathrm{s}\right)$ & $\left(\mathrm{m}^{3} / \mathrm{s}\right)$ & $(\mathrm{m} 3 / \mathrm{s})$ & & & \\
\hline 1.00 & 15.00 & 4.79 & 9.41 & 177.78 & 355.56 & 720 & 1440 & 0.25 & 0.20 & 19.80 \\
\hline 1.00 & 20.00 & 6.39 & 14.53 & 274.54 & 549.08 & 960 & 1920 & 0.29 & 0.22 & 22.24 \\
\hline 1.00 & 25.00 & 7.98 & 18.52 & 349.39 & 698.78 & 1200 & 2400 & 0.29 & 0.23 & 22.55 \\
\hline 1.00 & 30.00 & 9.58 & 23.30 & 440.00 & 880.00 & 1440 & 2880 & 0.31 & 0.23 & 23.40 \\
\hline 1.50 & 15.00 & 3.91 & 8.18 & 154.41 & 308.82 & 1080 & 2160 & 0.14 & 0.13 & 12.51 \\
\hline 1.50 & 20.00 & 5.21 & 12.82 & 242.41 & 484.82 & 1440 & 2880 & 0.17 & 0.14 & 14.41 \\
\hline 1.50 & 25.00 & 6.52 & 16.71 & 315.89 & 631.78 & 1800 & 3600 & 0.18 & 0.15 & 14.93 \\
\hline 1.50 & 30.00 & 7.82 & 21.65 & 409.17 & 818.34 & 2160 & 4320 & 0.19 & 0.16 & 15.93 \\
\hline 2.00 & 15.00 & 3.39 & 6.68 & 126.12 & 252.24 & 1440 & 2880 & 0.09 & 0.08 & 8.05 \\
\hline 2.00 & 20.00 & 4.52 & 13.00 & 245.59 & 491.18 & 1920 & 3840 & 0.13 & 0.11 & 11.34 \\
\hline 2.00 & 25.00 & 5.64 & 16.95 & 320.34 & 640.68 & 2400 & 4800 & 0.13 & 0.12 & 11.78 \\
\hline 2.00 & 30.00 & 6.77 & 21.13 & 399.50 & 799.00 & 2880 & 5760 & 0.14 & 0.12 & 12.18 \\
\hline
\end{tabular}

Havalandırma performansının Fr sayısıyla değişimi anlayabilmek için Şekil 7'deki grafik çizilmiştir. Görüleceği gibi ortalama hava konsantrasyonları Froude sayısıyla belirgin şekilde artmaktadır. Her bir su derinliği için değişimler lineer olmayan bir şekilde $\mathrm{Fr}=10$ değerine yaklaştıkça gittikçe azalan bir eğilim göstermektedir. $\mathrm{Bu}$ duruma göre, belirli bir akım derinliğinde hava konsantrasyonunun Fr sayısıyla sürekli olarak artmayacağı kritik bir Fr sayısından sonra (bu değer yaklaşık olarak $\mathrm{Fr}_{\mathrm{kr}}=10$ alınabilir) sabit kalacağı kabul edilebilir. Bu durumun muhtemelen havalandırmanın havalandırıcı kapasitesiyle sınırlı olmasından kaynaklanmaktadır.

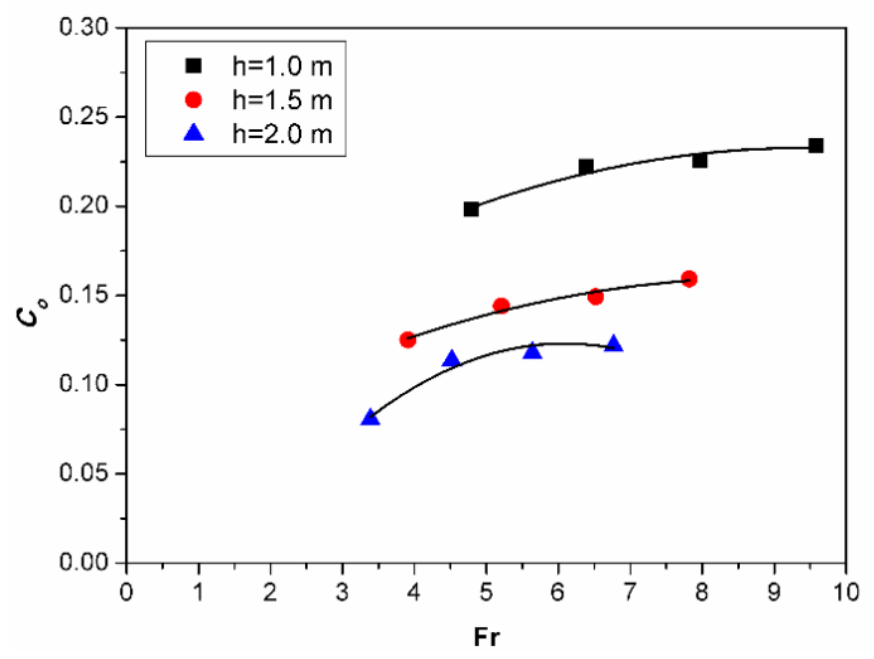

Şekil 7. Ilısu Barajı 2010 revize tasarımı ortalama hava konsantrasyonunun Froude sayısı ile değişimi 


\section{SONUÇLAR}

Bu çalışmada HAD analizleri yardımıyla Ilısu Barajı dolusavak ve havalandırıcı yapısının 1982 ve 2010 yılı tasarımlarının performansları değerlendirilmiştir. 1982 yılı tasarımı için DSİ tarafından bir dizi hidrolik model deneyleri yapılmış fakat 2010 revize tasarım için herhangi bir model deneyi yapılmamıştır. Bu nedenle 2010 yılı revize tasarımının sayısal modellemesi yapılarak farklı akım durumları için havalandırma performansları belirlenmeye çalışılmıştır. Elde edilen veriler ışığında; Ilısu Barajı dolusavak havalandırıcısının 1982 yılı tasarımının dolusavak şut kanalı üzerinde yeterli ve üniform bir hava konsantrasyonu sağlamadığı, bu bakımdan tasarımın kavitasyon hasarını önlemekte yetersiz kalabileceği ve yapılan revizyonun yerinde olduğu sonucuna varılmıştır. Bu kapsamda;

1. 1982 havalandırıcı tasarımı, yaklaşık olarak Froude sayısının 7.0'den küçük olduğu akım durumları için kavitasyondan korunmak için sağlanması gereken minimum hava konsantrasyonu (\%5) altında kalmaktadır.

2. Revize 2010 tasarımında ise ortalama hava konsantrasyonu \%8 23 aralığında elde edilmiştir.

3. Literatürdeki kaynaklara göre kavitasyondan korunmak için gerekli hava konsantrasyonu \%6-8 olduğu dikkate alındığında 1982 tasarımının havalandırma performansı bakımından yetersiz kaldığı, revize 2010 tasarımının ise oldukça yeterli bir performans sergilediği söylenebilir.

4. Aydın ve Kaplan (2015) $\mathrm{Fr}=4.06$ için $\beta=0.05$ ve buna bağlı olarak $C_{o}=\% 4.8$ olarak elde etmişse de faklı akım koşullarında bu çalışmada yapılan yeni analizlerde düşük Froude sayılarında bile $(\mathrm{Fr}<4)$ havalandırıcının yeterli hava konsantrasyonunu sağladığı görülmüştür $\left(C_{o}>\% 8\right)$.

5. Revize 2010 tasarımında sadece kenar duvarlarda havalandırıcı bacası bırakılmasına rağmen kanal genişliği boyunca kanal tabanında üniform bir basınç ve hava konsantrasyonu sağladığı görülmüştür. Yani kenar bacalardan giren hava altta dolusavak genişliği boyunca yerleştirilen hava kanalları sayesinde tüm genişlik boyunca yeterli bir hava karışımı sağlamakta ve böylelikle düşük Froude sayılarında bile havalandırıcı yeterli verimle çalışarak batık havalandırıcı durumunu önlemiş olacaktır.

\section{BILLGILENDIRME}

Bu çalışma Kaplan [27]'nın Yüksek Lisans Tezinden türetilmiştir.

\section{KAYNAKLAR}

[1] CHANSON, H., "Study of Air Entrainment and Aeration Devices", Journal of Hydraulic Research, 27(3), 301-319, 1989.

[2] CHANSON, H., "Study of Air Demand on Spillway Aerator", Journal of Fluid Engineering, 112(3), 343-350, 1990.

[3] CHANSON, H., "Aeration and Deaeration at Bottom Aeration Devices on Spillways", Canadian Journal of Civil Engineering, 21(3), 404-409, 1994.

[4] PINTO, N.L. De S., Cavitation and Aeration, Advanced Dam Engineering for Design, Construction, and Rehabilitation. Edited by R.B. Jansen, Kluver Academic Publishers, 620-634, 1988.

[5] VOLKART, P., ve CHERVET, A., Air Slots for Flow aeration, Mitteilung, 66, D. Vischer, ed., Laboratory of Hydraulics, Hydrology and Glaciology (VAW), ETH, Zurich, 1983.

[6] KELLS, J.A., ve SMITH, C.D., "Reduction of Cavitation on Spillways by Induced Air Entrainment", Canadian Journal of Civil Engineering, 18(3), 358-377, 1991.

[7] KOBUS, H. ve KOSCHITZKY, H. P., Local Surface Aeration at Hydraulic Structures, Air Entrainment in Free Surface Flows, Edited by I. R. Wood, A. A. Balkema Publications, Rotterdam, 29-54, 1991.

[8] RUTSCHMANN, P., "Calculation and Optimum Shape of Spillway Chute Aerators", Proceedings of The International Symposium on Model-Prototype Correlation of Hydraulic Structures, American Society of Civil Engineers /International Association For Hydraulic Research, Colorado Sprigs, Co, August 9-11, 118-128, 1988. 
[9] RUTSCHMANN, P., VOLKART, P., "Spillway Chute Aeration", Water Power and Dam Construction, 40(1), 10-15, 1988.

[10] RUTSCHMANN, P., HAGER, W.H., "Air Entrainment by Spillway Aerators", J. Hydraul. Eng., 116(6), 765-782, 1990.

[11] KÖKPINAR, M.A., ve GÖĞÜŞ, M., "High-speed jet flows over spillway aerators." Can. J. Civ. Eng., 29(6), 885-898, 2002.

[12] PFISTER, M., HAGER, W.H., "Chute Aerators. I: Air Transport Characteristics", J. Hydraul. Eng. 136, 352-359, 2010.

[13] PFISTER, M., HAGER, W.H., "Chute Aerators. II: Hydraulic Design”, J. Hydraul. Eng. 136, 360-367, 2010.

[14] PFISTER, M., LUCAS, J., HAGER, W.H., "Chute Aerators: Preaerated Approach Flow", J. Hydraulic Eng. 137, 1452-1461, 2011.

[15] QIAN, S., WU, J., MA, F., XU, J., PENG, Y., WANG, Z., "Cavity filling water control below aerator devices", Journal of Hydradynamics. 26(3), 424-430, 2014.

[16] AYDIN, M.C., Alttan Alışlı Dolusavak Havalandırıcıların CFD Analizi, Doktora Tezi, Fırat Üniversitesi Fen Bilimleri Enstitüsü, Elazığ, 2005.

[17] ÖZTÜRK, M., AYDIN, M.C., AYDIN, S., "Damage Limitation- A New Spillway Aerator", Int Water Power Dam Constr., 60(5), 36-40, 2008.

[18] AYDIN, M.C. "Aeration Efficiency of Bottom-inlet Aerators for Spillways", ISH Journal of Hydraulic Engineering, 24, 330-336, 2018.

[19] TENG, P., YANG, J., "CFD Modeling of Two-phase Flow of A Spillway Chute Aerator of Large Width", Journal of Applied Water Engineering and Research, 4(2), 163-177, 2016.

[20] KUMCU, S.Y., "Investigation of Flow Over Spillway Modeling and Comparison between Experimental Data and CFD Analysis", KSCE Journal of Civil Engineering, 21(3), 994-1003, 2017.

[21] DSİ, Ilısu Barajı ve HES İnşaatı Rehber Projeleri, Devlet Su İşleri Genel Müdürlügü, Ankara, 2010.

[22] AYDIN, M.C., IŞIK, E., "Using CFD in Hydraulic Structures", International Journal of Scientific and Technological Research, 1(5): 7-13, 2015.

[23] ANSYS-FLUENT, Fluent Theory Guide, ANSYS Help System, ANSYS Inc., 2012.

[24] RUSSELL, S.O., SHEENAN, G.J., "Effect of Entrained Air on Cavitation Damage", Canadian Journal of Civil engineering, 1(1), 97-107, 1974.

[25] AYDIN, M.C., Baraj Dolusavaklarında Havalandırma. Türkiye Alim Kitapları, Elazı̆̆g, 2016.

[26] AYDIN, M.C., KAPLAN C., "Ilısu Barajı ve HES Projesi Dolusavak Havalandırıcisının Performans Değerlendirmesi”, 4. Su Yapıları Sempozyumu, Bildiriler Kitabı, s:381-389, 19-21 Kasim, Antalya, 2015.

[27] KAPLAN, C. Ilısu Barajı Dolusavak Havalandırıcısının Performans Değerlendirmesi. Yüksek Lisans Tezi. Bitlis Eren Üniversitesi Fen Bilimleri Enstitüsü, Bitlis. 